\title{
A Report on the ESR and Magnetic Structure of $\mathrm{Bi}_{\mathrm{x}} \mathrm{Ca}_{1-\mathrm{x}} \mathrm{MnO}_{3}(\mathrm{x}=0.15,0.22)$
}

\author{
S. H. Na ${ }^{1 *}$, J. W. Kim ${ }^{1}$, S. N. Choi ${ }^{2}$, and J. W. Park ${ }^{1}$ \\ ${ }^{1}$ Department of Physics, Pusan National University, Pusan 609-735, Korea \\ ${ }^{2}$ Department of Chemistry, Pusan National University, Pusan 609-735, Korea
}

(Received 19 December 2005)

\begin{abstract}
The electron spin resonance signals of $\mathrm{Bi}_{\mathrm{x}} \mathrm{Ca}_{1-\mathrm{x}} \mathrm{MnO}_{3}$ have been acquired for two samples of $\mathrm{x}=0.15$ and 0.22 . ESR signal of the sample of $x=0.15$ clearly shows signal shape change into Dysonian with g-value shift at around $165 \mathrm{~K}$ so that the charge ordering temperature can be identified. The general features of ESR signal of the two samples well correlate with magnetic susceptibility measurement and also confirm the validity of former investigations.
\end{abstract}

Key words : electron spin resonance, g-value, charge ordering

\section{Introduction}

$\mathrm{Bi}_{\mathrm{x}} \mathrm{Ca}_{1-\mathrm{x}} \mathrm{MnO}_{3}$ is one of the perovskite mixed-valent manganites sometimes called TDMO family materials (T: trivalent, D: divalent) having the property of colossal magnetoresistence, i.e. great reduction of resistivity under existence of magnetic field. The temperature dependences of resistivity and magnetic susceptibility of $\mathrm{Bi}_{\mathrm{x}} \mathrm{Ca}_{1-\mathrm{x}} \mathrm{MnO}_{3}$ as well as its crystal structure have been closely examined $[1,2]$.

Magnetic phase of $\mathrm{Bi}_{\mathrm{x}} \mathrm{Ca}_{1-\mathrm{x}} \mathrm{MnO}_{3}$ is rather complicated

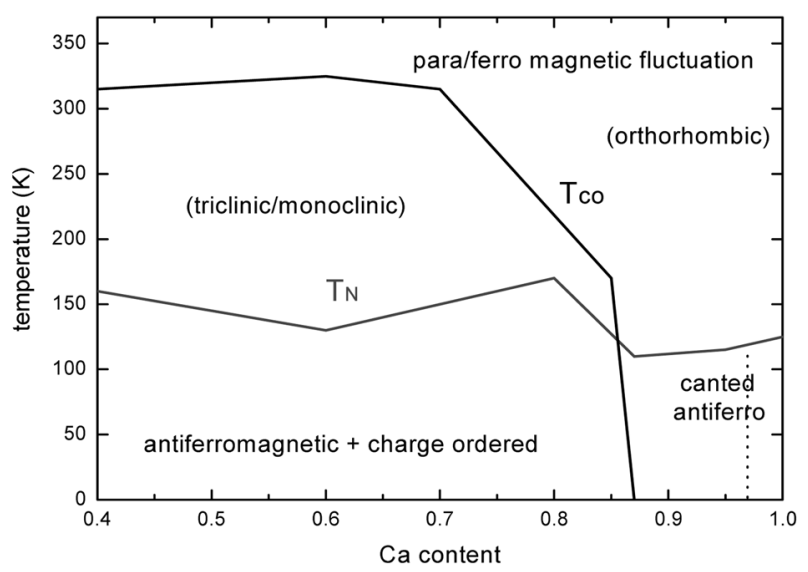

Fig. 1. Summary of phase diagram of the BCMO system (after Woo et al., 2001).

*Corresponding author: Tel: +82-51-510-1769,

Fax: +82-51-513-7664, e-mail: sunghona@pusan.ac.kr and is varying with the differing content of bismuth/ calcium and also with differing temperature. Although other measurements have been formerly used to identify charge ordering temperature of $\mathrm{Bi}_{\mathrm{x}} \mathrm{Ca}_{1-\mathrm{x}} \mathrm{MnO}_{3}$, we found that it can be easily and accurately done by electron spin resonance absorption signal for certain cases such as for $\mathrm{Bi}_{0.15} \mathrm{Ca}_{0.85} \mathrm{MnO}_{3}$.

It is quite often the case that ESR signals of $\mathrm{Bi}_{\mathrm{x}} \mathrm{Ca}_{1-\mathrm{x}} \mathrm{MnO}_{3}$ are small at room temperature but they become large enough to be detected at lower temperature particularly around charge ordering temperature and Neel temperature.

\section{Experiment}

Samples of $\mathrm{Bi}_{\mathrm{x}} \mathrm{Ca}_{1-\mathrm{x}} \mathrm{MnO}_{3}$ crystal were synthesized by flux method. Mixtures of $\mathrm{Bi}_{2} \mathrm{O}_{3}, \mathrm{CaCO}_{3}, \mathrm{MnO}_{2}$ powders were reacted at $1443 \mathrm{~K}$ for several days in air. Compositions were identified by EPMA analysis [3].

Two samples $\mathrm{Bi}_{\mathrm{x}} \mathrm{Ca}_{1-\mathrm{x}} \mathrm{MnO}_{3}$ with $\mathrm{x}=0.15$ and 0.22 have been examined by electron spin resonance (X-band), magnetic susceptibility measurement, and X-ray diffraction. Temperature ranges for ESR experiment and magnetic susceptibility measurement in this study were $120-400 \mathrm{~K}$ and $120-300 \mathrm{~K}$ respectively.

\section{Result and Discussion}

The X-ray diffraction patterns of the powders of $\mathrm{Bi}_{\mathrm{x}} \mathrm{Ca}_{1-\mathrm{x}} \mathrm{MnO}_{3}$ samples are in Fig. 2. Peak angles of 


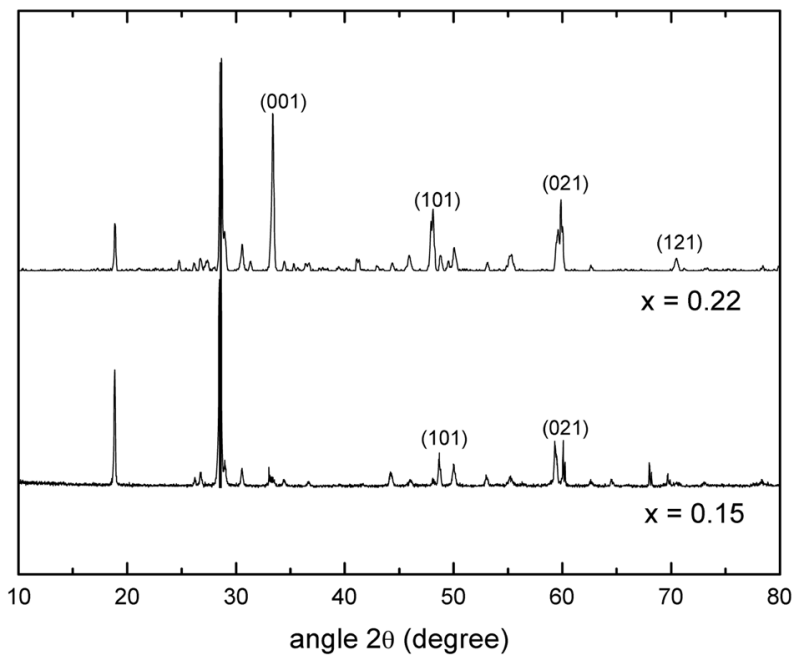

Fig. 2. $\mathrm{X}$-ray diffraction of the samples of $\mathrm{Bi}_{\mathrm{x}} \mathrm{Ca}_{1-\mathrm{x}} \mathrm{MnO}_{3}$ with $\mathrm{x}=0.22$ and 0.15 (index based on pseudo cubic approximation).

$2 \theta=33.4,48.1$, and 59.9 are slightly shifted from those of $\mathrm{CaMnO}_{3}$ and these shifts are due to slight expansion of lattice with $\mathrm{Bi}$ content. Two conspicuous peaks of $2 \theta=$ 18.9 and 28.6 are believed to be associated with planes made of excessive amount of bismuth.

Magnetic susceptibility measurements were done by using Vibrating Sample Magnetometer for temperature range from room temperature down to $120 \mathrm{~K}$ and the some major parts are shown in Figure 3-4.

At each given temperature $\mathrm{BCMO}$ samples show stable paramagnetic behavior except that the sample of $\mathrm{x}=0.22$ shows a little bit of instability for magnetic field larger than 3000 Oe. Temperature dependences of the magnetic susceptibilities of the two samples in Figure 5 are different from each other and show rather complicated characteristics. It is believed that maximum at $160 \mathrm{~K}$ for

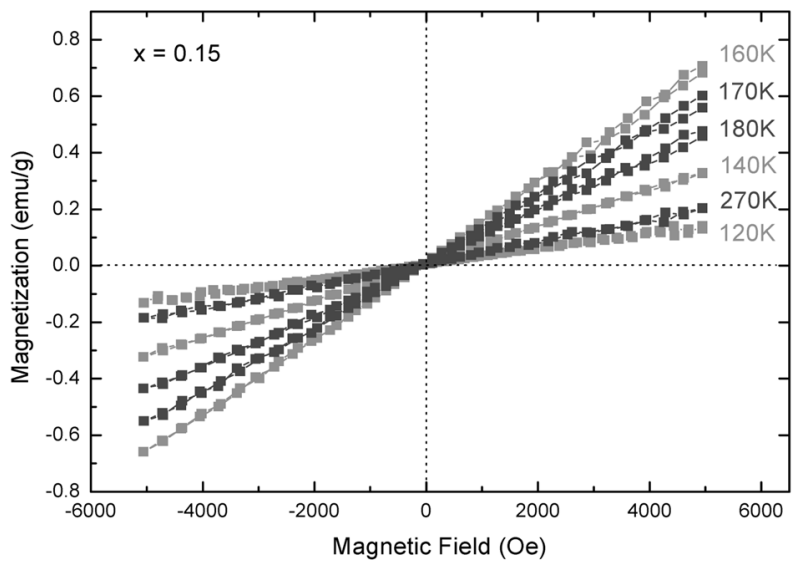

Fig. 3. Induced Magnetizations of the sample of $\mathrm{Bi}_{\mathrm{x}} \mathrm{Ca}_{1-\mathrm{x}} \mathrm{MnO}_{3}$ with $\mathrm{x}=0.15$.

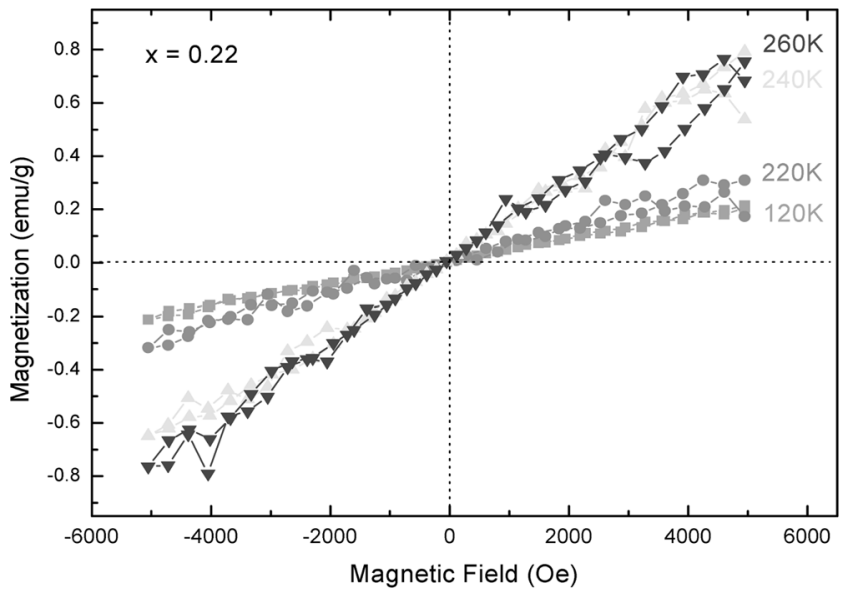

Fig. 4. Induced Magnetizations of the sample of of $\mathrm{Bi}_{\mathrm{x}} \mathrm{Ca}_{1-\mathrm{x}} \mathrm{MnO}_{3}$ with $\mathrm{x}=0.22$.

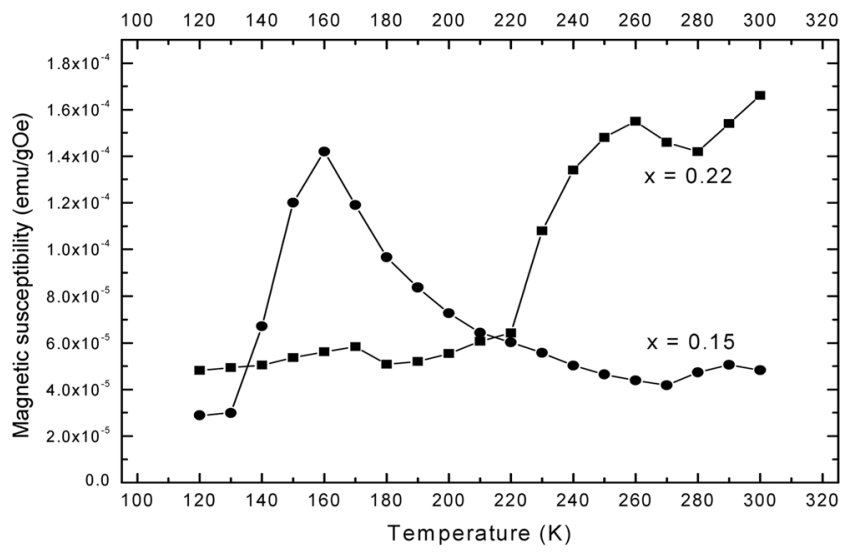

Fig. 5. Temperature dependences of the magnetic susceptibility of $\mathrm{Bi}_{\mathrm{x}} \mathrm{Ca}_{1-\mathrm{x}} \mathrm{MnO}_{3}$.

the sample with $\mathrm{x}=0.15$ is associated with charge ordering as former study. $260 \mathrm{~K}$ and $170 \mathrm{~K}$ are regarded as charge ordering temperature and Neel temperature of the sample with $\mathrm{x}=0.22$ accordingly.

Electron spin resonance absorption signal of the two samples are in Figure 6 and 7. These are acquired by detecting conventional X-band microwave absorption by the sample under magnetic field at each temperature maintained by controlled nitrogen gas flow with heating.

The ESR differential absorption curves acquired are mostly Lorentian. Evidently close correlation exists between VSM measurement and ESR signal. But they do not exactly match in all temperature range. For the sample of $\mathrm{x}=0.22$, ESR absorption is maximum at $\mathrm{T}=240 \mathrm{~K}$ rather than $250,260 \mathrm{~K}$ and ESR absorption at around room temperature or at $\mathrm{T}<200 \mathrm{~K}$ is smaller than expected from magnetic susceptibility value. For the sample of $\mathrm{x}=$ 0.15 , the signal shape changes from Lorentian for $\mathrm{T}>170 \mathrm{~K}$ 


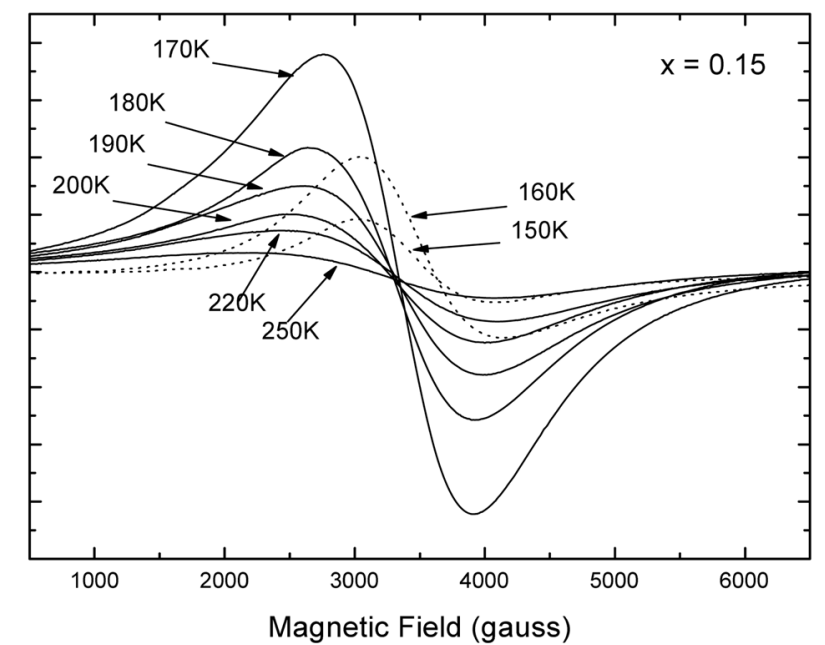

Fig. 6. ESR signals of the sample $\mathrm{Bi}_{\mathrm{x}} \mathrm{Ca}_{1-\mathrm{x}} \mathrm{MnO}_{3}$ with $\mathrm{x}=0.15$.

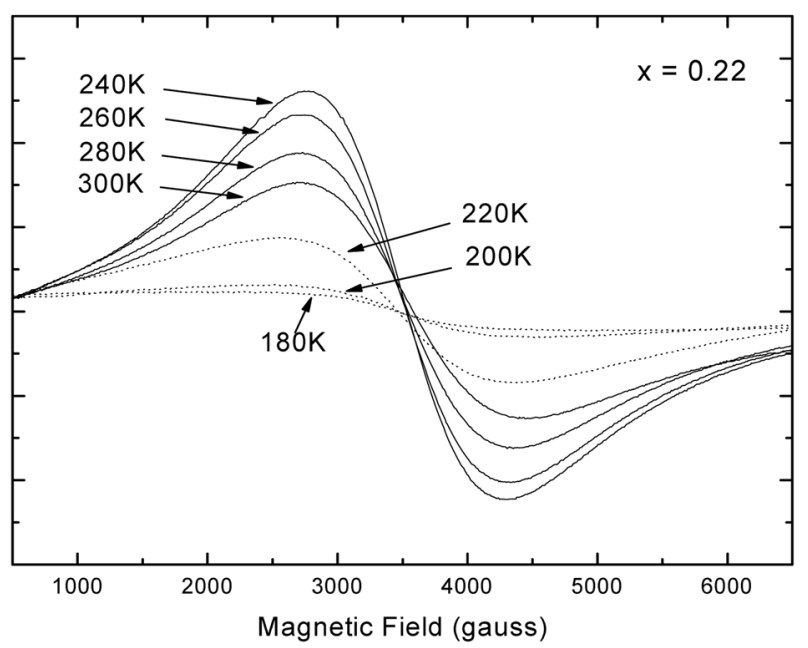

Fig. 7. ESR signals of the sample $\mathrm{Bi}_{\mathrm{x}} \mathrm{Ca}_{1-\mathrm{x}} \mathrm{MnO}_{3}$ with $\mathrm{x}=0.22$.

to Dysonian for $\mathrm{T}<160 \mathrm{~K}$. And also the g-value shift is evidently shown with this temperature change. From the
BCMO phase diagram after Woo et al. it is believed this temperature is related with two phenomena, charge ordering and antiferromagnetic spin ordering. According to their diagram, Tco and $\mathrm{T}_{\mathrm{N}}$ are close to each other at this temperature for this sample. From the magnetic susceptibility alone, it is difficult to tell that charge ordering also occurs above/below the Neel temperature. But we can speculate from the ESR signal that charge ordering is coexistent and may be dominant because the Dysonian shape of ESR differential absorption curve is usually acquired for low conducting materials [4]. The charge ordering of the BCMO sample of $\mathrm{x}=0.22$ is quite possibly more gradual at temperature below Tco than that of the other sample. $T_{N}$ of the sample of $x=0.22$ is identified as $170 \mathrm{~K}$ from magnetic susceptibility curve.

\section{Acknowledgment}

BCMO crystals of this study were kindly supported by Dr. Boggi Kim in the Department of Physics, PNU. The authors appreciate encouragement and support of Dr. Eatons in University of Denver. Correspondence with Dr. Weber in Bruker BioSpin Corp. is also appreciated. The authors thank Dr. Won in KBSI for access to electron magnetic resonance spectrometer.

\section{References}

[1] H. Woo, T. A. Tyson, M. Croft, S-W. Cheong, and J. C. Woicik, Phys. Rev. B 63, 134412 (2001).

[2] K. A. Krezhov, BPU-5, Fifth Gen. Conf. Balkan. Phys. Union, 2203 (2003).

[3] K. H. Kim, C. H. Kim, J. H. Cho, and B. G. Kim, SAE MULLI, 49(2), 191-196, (2004).

[4] G. Feher and A. F. Kip, Phys. Rev. 98(2), 337-348 (1955), and F. J. Dyson, ibid, 349-359. 